\title{
Epigenetic Mechanisms of Pituitary Cell Fate Specification
}

\author{
Jacques Drouin
}

\begin{abstract}
Pituitary progenitor or stem cells present in the pituitary primordium during development are the source of hormone-producing cells of the adult pituitary. These stem cells are maintained in the adult tissue and they can be recruited to maintain or replenish differentiated pituitary cells. We currently have only limited insight into the mechanisms that trigger progenitor engagement into one or the other pituitary differentiation pathway. While transcription factors that drive terminal differentiation have been identified for different lineages, current evidence suggests that initial engagement of progenitors into differentiation may be due to earlier-acting factors. One such factor expressed at the transition between progenitor and differentiated state was identified in the intermediate lobe; this factor, Pax7, exerts its action through a pioneer factor activity. Pioneer transcription factors have the unique ability to bind target sequences in compacted chromatin and to initiate chromatin "opening" for recruitment of other transcription factors. Pax7 accomplishes this process on about 2500 enhancers genome-wide, allowing for Tpit recruitment at a subset for implementation of the melanotrope-specific program of gene expression. Current knowledge about this process is reviewed here, together with a discussion of future challenges in order to understand the unique properties of pioneer transcription factor action and cell reprogramming through chromatin remodelling.
\end{abstract}

\section{Introduction}

The last decade was rich in surprising discoveries about the organization and function of the pituitary. Indeed, we realized that pituitary cells are organized in a series of intimately associated homotypic cell networks that serve to coordinate tissue response (Mollard et al. 2012). Further, the pituitary, like many other tissues,

\footnotetext{
J. Drouin $(\bowtie)$

Laboratoire de Génétique Moléculaire, Institut de Recherches Cliniques de Montréal (IRCM), 110, avenue des Pins Ouest, Montréal, QC, Canada, H2W 1R7

e-mail: jacques.drouin@ircm.qc.ca

(C) The Author(s) 2016

D. Pfaff, Y. Christen (eds.), Stem Cells in Neuroendocrinology, Research and

Perspectives in Endocrine Interactions, DOI 10.1007/978-3-319-41603-8_9
} 
was found to contain a population of stem or progenitor cells that are maintained in adult tissues (Rizzoti 2015); this population of pituitary progenitors itself forms a homotypic network that is primarily organized around the cleft between the intermediate and anterior pituitary (Gremeaux et al. 2012). Signals that activate the progenitors to either proliferate or differentiate are still being investigated, but clearly these mechanisms provide a unique opportunity to think about new therapeutic perspectives to treat pituitary hormone deficiencies.

To capitalize on the properties of pituitary stem or progenitor cells for any kind of replacement therapy requires that we understand the unique properties of these cells and, most importantly, the mechanisms that engage stem cells into differentiation pathways. Pituitary progenitors can differentiate into each of the pituitary lineages (Fauquier et al. 2008); the challenge is then to understand the precise requirements for differentiation into each lineage. While a number of critical transcription factors have been identified for their role in terminal differentiation of most lineages (Rizzoti 2015), such as Pit1, Tpit and SF1, the initial events of entry into differentiation are the ones that we least understand presently.

This review will focus on one particular factor that appears to represent such an initial event for engagement into the differentiation pathway, Pax7, which selects intermediate lobe identity. Pax 7 is unique among the transcription factors presently identified for a role in pituitary cell differentiation in that it possesses pioneer activity (Budry et al. 2012). Few transcription factors have the pioneer ability to bind "closed" or compacted chromatin and to trigger chromatin remodeling of regulatory sequences, thus opening not only chromatin structure but, most importantly, a new program of gene expression (Iwafuchi-Doi and Zaret 2014).

\section{Escaping Stemness}

Stem cells, whether pluripotent or tissue-specific, have unique properties with regards to basic cell physiology compared to differentiated cells (De Los Angeles et al. 2015). The engagement of stem cells into a differentiation pathway thus implies an important switch for many cellular functions in addition to the gain of expression for the unique genetic program of the chosen differentiation path. For example, this can include a switch in energy metabolism (Kohli and Passegue 2014); for pituitary progenitors, it was shown that the control of cell cycle re-entry is very different in progenitors compared to differentiated cells (Bilodeau et al. 2009). Indeed during normal mouse development, pituitary progenitors marked by expression of Sox 2 (Fauquier et al. 2008) exit the cell cycle under the action of the Cip-Kip inhibitor p5 $7^{\mathrm{Kip} 2}$ whereas, upon differentiation, the role of keeper of cell cycle re-entry is taken over by the related p27 $7^{\mathrm{Kip} 1}$ (Fig. 1a). Although replacing one inhibitor by a related one may appear as switching between redundant regulators, the situation is likely more complex, since knockout mice for $\mathrm{p} 57^{\mathrm{Kip} 2}$ do eventually switch-on expression of $\mathrm{p} 27^{\mathrm{Kip} 1}$ with rescue of some differentiated cells; however, in the delayed progenitor compartment where this switch has not 


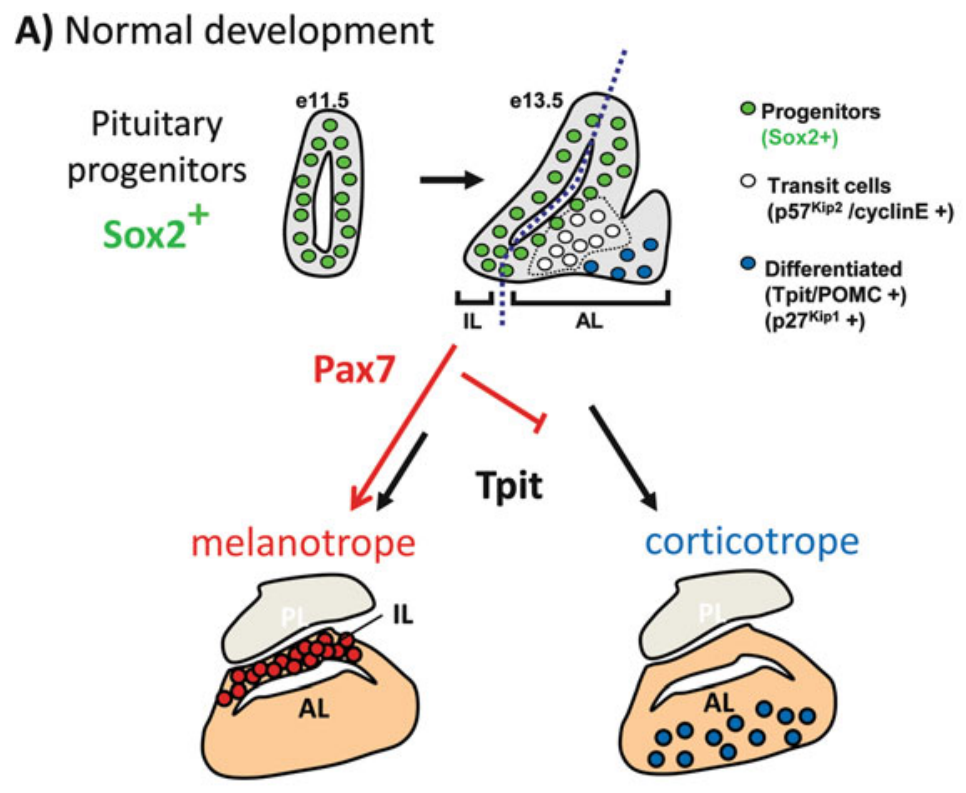

B) Gain-of-function - Increased active enhancer repertoire

AtT-20+Pax7 cells
melanotrope-like

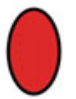

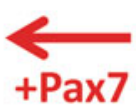

AtT-20 cells corticotrope

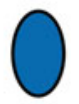

\section{8 new enhancers}

new Pax7, H3K4me1, p300
46859 enhancers

p300 present

\section{new Tpit at 824 enhancers}

Fig. 1 Role of Pax7 in pituitary development. (a) The role of Pax7 in normal pituitary development is depicted in the context of the engagement of Sox2-positive pituitary progenitors into differentiation pathways. Pituitary progenitors are present throughout the pituitary primordium, Rathke's pouch, and the early pituitary depicted here at day e11.5 of mouse embryonic development. The Sox2-positive progenitors (green) proliferate and, starting at e12, a group of Sox2negative, $\mathrm{p} 57^{\mathrm{Kip} 2}$ - and cyclinE-positive cells (white) appears on the ventral side of the pituitary cleft: these cells have features of transitory precursors. The first differentiated cells appear on the ventral surface of the developing anterior lobe: these are Tpit-positive corticotropes (blue) that no longer express $\mathrm{p} 57^{\mathrm{Kip} 2}$ and CyclinE but rather $\mathrm{p} 27^{\mathrm{Kip} 1}$. Starting at e14, intermediate lobe (IL) cells express Pax7 followed by Tpit and later POMC. Anterior lobe (AL) corticotropes never express Pax7 and differentiate following expression of Tpit. (PL is posterior lobe). (b) Gain-of-function for Pax7 performed in corticotrope AtT-20 cells reveals the pioneer transcription factor activity of Pax7. The expression of Pax7 in AtT-20 cells reprograms the cells to become melanotrope-like (Budry et al. 2012). The action of Pax7 on the AtT-20 epigenome results in activation of 2508 new enhancers that have all the expected chromatin hallmarks; 824 of them can then recruit Tpit 
occurred, massive apoptosis occurs, which is suggestive of a critical role for $\mathrm{p} 57^{\mathrm{Kip} 2}$ in leaving the stem status.

Little is known about this switch from stem to differentiated state but, during development, it appears as sequential steps that are separated by a transitory period/ state where cells have lost markers of stemness such as Sox 2 but not yet gained markers of differentiation such as expression of terminal differentiation factors like Pit1 and Tpit (Bilodeau et al. 2009). Cells undergoing this transitory period have been highlighted in the developing anterior pituitary but effectors of this transition remain to be identified. The big question is thus: what is happening to the genetic program of these transitory precursors? Are they being pre-programmed for leaving the stem state and for entry into one or the other pituitary differentiation pathway? Is their epigenome being set for establishment of a differentiation program?

In the intermediate pituitary, a transcription factor essential for intermediate lobe identity and melanotrope differentiation was identified and it appears to act within this gap between stem and differentiation states. Indeed, the transcription factor Pax7 is expressed immediately after extinction of Sox 2 , such that a small number of co-expressing cells can be visualized in the developing mouse pituitary (Budry et al. 2012). It is only about a half-day later that the driver of terminal differentiation, Tpit, is expressed in Pax7-positive cells, leading to expression of melanotrope genes (Fig. 1a).

Pax7 thus has the hallmark of a factor that would engage progenitors into a differentiation pathway and prepare transitory precursors for implementation of the terminal differentiation program that is itself directed by the Tbox factor Tpit. A factor with similar properties has yet to be discovered in the anterior pituitary.

\section{Intermediate Pituitary Identity}

The intermediate lobe melanotropes are one of the two pituitary lineages that express the single copy POMC gene. Terminal differentiation of both POMC lineages, the melanotropes and the corticotropes of the anterior lobe, requires the action of the Tbox transcription factor Tpit (Lamolet et al. 2001; Pulichino et al. 2003). Consistent with this role of Tpit as driver of terminal differentiation, Tpit is required for transcription of the POMC gene in both lineages and it acts genome-wide on an extensive program of gene expression (Langlais et al. 2011). Obviously by playing this role for both POMC lineages, Tpit cannot explain the unique features of melanotrope compared to corticotropes, the two lineages fulfilling entirely different biological functions and, accordingly, being regulated by very different signals.

The quest for transcription factor(s) that may account for the unique program of each lineage led to identification of $\operatorname{Pax} 7$ for its unique expression in the intermediate lobe melanotropes (Budry et al. 2012). The differentiation of most cell lineages requires the combinatorial action of many transcription factors that together control cell-specific gene expression. While it is in this context that Pax7 
was initially investigated, it rapidly became clear that Pax7 has far more reaching actions on the epigenome and that it reprograms intermediate lobe cells for their unique purpose. Hence in $\operatorname{Pax} 7$ knockout pituitaries, intermediate lobe cells still differentiate under the action of Tpit but, being deprived of Pax7, the cells switch fate and differentiate into corticotropes (Budry et al. 2012). This process is exemplified by the failure to activate melanotrope-specific genes such as the $P C 2$ gene, which encodes the protein convertase responsible for cleaving ACTH into $\alpha \mathrm{MSH}$, and also by repression of corticotrope-specific genes such as those for $\mathrm{CRH}$ and vasopressin receptors. This situation is very different in comparison to the Tpit knockout intermediate lobe, where cells fail to differentiate into either melanotrope or corticotrope but stay, for the most part, in a limbo between stem and differentiated states; for example, these cells co-express the two cell cycle inhibitors $\mathrm{p} 57^{\mathrm{Kip} 2}$ and $\mathrm{p} 27^{\mathrm{Kip} 1}$, a situation that is never observed normally. Thus, Pax 7 itself does not drive expression of the differentiation program but rather sets the stage for Tpit action.

\section{Pax7 Opens a New Enhancer Repertoire}

The unique property of $\operatorname{Pax} 7$ to act as a pioneer transcription factor allows it to pre-program intermediate lobe precursors towards the melanotrope identity that will be later implemented by Tpit (Budry et al. 2012). The picture that is emerging with regards to pioneer factor action is still fragmentary, but the few pioneers that have been characterized may operate at different levels to remodel chromatin. Whereas the pluripotency factors Sox2, Oct4 and Klf4 initiate chromatin remodeling over large spans of the genome (Soufi et al. 2012), factors like FoxA (Cirillo et al. 2002), C/EBP $\alpha$ (van Oevelen et al. 2015), Ascl1(Wapinski et al. 2013) and Pax 7 that are involved in specific-tissue programming act primarily on the enhancer repertoire by both locally opening chromatin at some enhancers and closing others for activity. The opening or priming of a new enhancer repertoire will de facto implement the possibility for a new program of gene expression and, indeed, this is what is observed in pituitary cells following Pax7 action: Tpit now gains access to a completely new set of enhancers (Fig. 1b). In gain-of-function experiments performed in AtT-20 cells, Pax 7 triggered the local appearance of active chromatin marks at 2500 enhancers and, of those, 824 became new targets of Tpit. Genome-wide, Pax7 targeted an enhancer repertoire that largely $(73 \%)$ overlapped the Tpit target repertoire (Budry et al. 2012). The PC2 (PCSK2) locus provides a good example of this: indeed in normal corticotrope AtT-20 cells, this gene is inactive and its enhancer bears no mark of active chromatin. Following Pax7 action, an enhancer located $146 \mathrm{~Kb}$ upstream of the $P C 2$ transcription start site became active, as revealed by a variety of chromatin marks. Indeed, the enhancer acquired a bimodal distribution of histone H3K4me1 and the enhancer DNA became accessible where it was depleted of nucleosome. Also, the general co-activator p300 was recruited to the enhancer together with Tpit (Fig. 1b). This 
evolutionarily conserved enhancer thus has all the hallmarks of a Pax7- and Tpitdependent enhancer (Budry et al. 2012).

In contrast to the pluripotency factors that have large-scale effects on chromatin organization, the action of Pax7 is restricted to a subset of enhancer domains. It is interesting that, in the AtT-20 cell gain-of-function experiments, Pax 7 also partially repressed expression of corticotrope-specific genes and this was accompanied by a quantitative decrease in chromatin marks. However, the extinction of corticotropespecific enhancers was at best partial in this model. Nonetheless, these observations indicate that Pax7 has the ability to not only activate a subset of enhancers but also to repress others, a property that is shared with other pioneer factors (Watts et al. 2011; Wang et al. 2015).

\section{The Essence of Pioneering}

The critical property of pioneer factors is that they can access their target DNA sequence in so-called "closed" or compacted heterochromatin. This unique property was well illustrated for Pax7 in comparison to Tpit at the $P C 2$ gene $-146 \mathrm{~Kb}$ enhancer, where Tpit could not gain access to its well-conserved palindromic target sequence if Pax7 had not previously directed local chromatin remodeling of the enhancer (Budry et al. 2012). How pioneer factors gain access to their sites in "closed" chromatin remains largely open to question. While some target binding sites may find themselves exposed on the surface of nucleosomal DNA, the random possibility of such positioning argues against this sole mechanism in view of the high selectivity exerted by pioneer factors. Some pioneers such as FoxA may initially bind its targets with decreased specificity to scan the genome and then bind more firmly at pioneering sites (Soufi et al. 2015), but this still does not explain why a specific subset of sites is selected. The winged helix DNA binding domain of FoxA factors may mimic the structure of the histone H1 linker that interacts with DNA to stabilize interaction with nucleosomal DNA (Cirillo and Zaret 2007), but this model will not apply to all pioneers such as for Pax7. Some factors interact with core histones, which may stabilize their association with chromatin (Cirillo et al. 2002; Fiedler et al. 2008). Other factors like the Sox family interact with the minor groove of DNA and that may facilitate recognition of target sequences on nucleosomes, but again, this property is not relevant for all pioneers.

For the melanotrope-specific enhancers pioneered by Pax7, the analysis of enhancers that contain only one sequence motif for Pax7 binding showed that the group of enhancers that have a so-called composite motif was specifically associated with pioneering sites (Budry et al. 2012). This composite target site contained each of the DNA sequences corresponding to the two DNA binding domains of Pax7, the paired and the homeo domains. In contrast, the enhancers that contained only the paired or homeodomain target sequence were primarily associated with enhancers that were already accessible and targeted by Pax7 for transcriptional activation without pioneering (Budry et al. 2012). Since the composite site was 
longer than either paired or homeodomain target sites, it is possible that higher affinity for this site may contribute to the ability to pioneer chromatin remodeling. Alternatively, it may also be that Pax7 interaction with the composite site involves a unique conformation of the Pax7 DNA binding domains that is itself required to initiate pioneering events.

Indeed, a unique conformation of the pioneer may be needed to recruit chromatin remodeling complexes that initiate the replacement of modified histone from repressive to active forms of histones. The sequence of biochemical changes required to establish a new stable chromatin environment at active enhancers remains poorly defined. In some systems, changing the chromatin environment requires passage through DNA replication, hence stripping of chromatin to re-establish a new chromatin environment (MacAlpine and Almouzni 2013; Nashun et al. 2015). It is an open question whether passage through DNA replication is needed for all pioneers (Iwafuchi-Doi and Zaret 2014), but for Pax7, the activation of target genes that require pioneering is far slower than for transcriptional activation of enhancers/genes that are already in an open active chromatin conformation. Hence, the action of Pax7 on chromatin remodeling may require passage through DNA replication.

\section{Succeeding at Multiple Choices or Avoiding Cellular Schizophrenia}

Pax7 is an interesting study case for pioneering. Indeed, we have shown a critical role for Pax7 in the establishment of intermediate pituitary identity and setting-up of the melanotrope program of gene expression, but the same Pax7 is also critical for the myogenic program of gene expression, where it is expressed at the transition between progenitor and differentiated skeletal muscles (Buckingham and Rigby 2014). These two entirely different functions of $\operatorname{Pax} 7$ are not compatible with each other and, despite the ability of Pax7 to recognize its target DNA sites in heterochromatin, it would need to distinguish the pituitary versus muscle targets in order to appropriately play its role in each tissue. How is this achieved? There is currently no clue on how this discrimination is exerted! The myogenic targets of Pax7 are not bound by Pax7 in pituitary cells, despite the fact that a large group of Pax7 target sites present in heterochromatin (marked with high levels of histone H3K9me3, the hallmark of heterochromatin) are bound by Pax7 in pituitary cells. Unexplainably, the myogenic targets of Pax7 exhibit lower levels of the repressive H3K9me3 in the same pituitary cells and yet are not bound by Pax7. Without providing an explanation, these observations nonetheless clearly indicate that we have much to learn about the nature of so-called "closed" chromatin and that there likely are many flavors of heterochromatin that remain to be defined. 


\section{Future Challenges}

The above discussion has illustrated how pioneer transcription factors are important to implement the developmental program through their unique properties to (1) recognize their DNA targets on "closed" chromatin and (2) initiate chromatin remodeling either in a localized fashion at specific enhancers or more broadly on large genomic domains. It is critical to understand these processes in order to master cellular reprogramming for therapeutic uses.

In the context of pituitary development, we have reason to believe that there may be one or more pioneer factors that establish competence towards anterior pituitary lineages, and we would expect these factors to exert their critical function during the developmental window when fetal pituitary progenitors have lost expression of stem cell markers such as Sox 2 but not yet gained expression of terminal differentiation drivers such Tpit or Pit1. Is there one pioneer for anterior pituitary identity that allows differentiation toward each of the five anterior lobe lineages or are there two for each of the related subgroups of lineages, the gonadotrope and corticotrope subgroup and the Pit-dependent subgroup? These are important questions that demand investigation.

Open Access This chapter is distributed under the terms of the Creative Commons Attribution 4.0 International License (http://creativecommons.org/licenses/by/4.0/), which permits use, duplication, adaptation, distribution and reproduction in any medium or format, as long as you give appropriate credit to the original author(s) and the source, a link is provided to the Creative Commons license and any changes made are indicated.

The images or other third party material in this chapter are included in the work's Creative Commons license, unless indicated otherwise in the credit line; if such material is not included in the work's Creative Commons license and the respective action is not permitted by statutory regulation, users will need to obtain permission from the license holder to duplicate, adapt or reproduce the material.

\section{References}

Bilodeau S, Roussel-Gervais A, Drouin J (2009) Distinct developmental roles of cell cycle inhibitors p57Kip2 and p27Kip1 distinguish pituitary progenitor cell cycle exit from cell cycle re-entry of differentiated cells. Mol Cell Biol 29:1895-1908

Buckingham M, Rigby PW (2014) Gene regulatory networks and transcriptional mechanisms that control myogenesis. Dev Cell 28:225-238

Budry L, Balsalobre A, Gauthier Y, Khetchoumian K, L'honore A, Vallette S, Brue T, FigarellaBranger D, Meij B, Drouin J (2012) The selector gene Pax7 dictates alternate pituitary cell fates through its pioneer action on chromatin remodeling. Genes Dev 26:2299-2310

Cirillo LA, Zaret KS (2007) Specific interactions of the wing domains of FOXA1 transcription factor with DNA. J Mol Biol 366:720-724

Cirillo LA, Lin FR, Cuesta I, Friedman D, Jarnik M, Zaret KS (2002) Opening of compacted chromatin by early developmental transcription factors HNF3 (FoxA) and GATA-4. Mol Cell 9:279-289 
De Los AA, Ferrari F, Xi R, Fujiwara Y, Benvenisty N, Deng H, Hochedlinger K, Jaenisch R, Lee S, Leitch HG, Lensch MW, Lujan E, Pei D, Rossant J, Wernig M, Park PJ, Daley GQ (2015) Hallmarks of pluripotency. Nature 525:469-478

Fauquier T, Rizzoti K, Dattani M, Lovell-Badge R, Robinson IC (2008) SOX2-expressing progenitor cells generate all of the major cell types in the adult mouse pituitary gland. Proc Natl Acad Sci USA 105:2907-2912

Fiedler M, Sanchez-Barrena MJ, Nekrasov M, Mieszczanek J, Rybin V, Muller J, Evans P, Bienz M (2008) Decoding of methylated histone H3 tail by the Pygo-BCL9 Wnt signaling complex. Mol Cell 30:507-518

Gremeaux L, Fu Q, Chen J, Vankelecom H (2012) Activated phenotype of the pituitary stem/ progenitor cell compartment during the early-postnatal maturation phase of the gland. Stem Cells Dev 21:801-813

Iwafuchi-Doi M, Zaret KS (2014) Pioneer transcription factors in cell reprogramming. Genes Dev 28:2679-2692

Kohli L, Passegue E (2014) Surviving change: the metabolic journey of hematopoietic stem cells. Trends Cell Biol 24:479-487

Lamolet B, Pulichino AM, Lamonerie T, Gauthier Y, Brue T, Enjalbert A, Drouin J (2001) A pituitary cell-restricted T-box factor, Tpit, activates POMC transcription in cooperation with Pitx homeoproteins. Cell 104:849-859

Langlais D, Couture C, Sylvain-Drolet G, Drouin J (2011) A pituitary-specific enhancer of the POMC gene with preferential activity in corticotrope cells. Mol Endocrinol 25:348-359

MacAlpine DM, Almouzni G (2013) Chromatin and DNA replication. Cold Spring Harbor Perspec Biol 5:a010207

Mollard P, Hodson DJ, Lafont C, Rizzoti K, Drouin J (2012) A tridimensional view of pituitary development and function. Trends Endocrinol Metab 23:261-269

Nashun B, Hill PW, Hajkova P (2015) Reprogramming of cell fate: epigenetic memory and the erasure of memories past. Embo J 34:1296-1308

Pulichino AM, Vallette-Kasic S, Tsai JP, Couture C, Gauthier Y, Drouin J (2003) Tpit determines alternate fates during pituitary cell differentiation. Genes Dev 17:738-747

Rizzoti K (2015) Genetic regulation of murine pituitary development. J Mol Endocrinol 54: R55-73

Soufi A, Donahue G, Zaret KS (2012) Facilitators and impediments of the pluripotency reprogramming factors' initial engagement with the genome. Cell 151:994-1004

Soufi A, Garcia MF, Jaroszewicz A, Osman N, Pellegrini M, Zaret KS (2015) Pioneer transcription factors target partial DNA motifs on nucleosomes to initiate reprogramming. Cell 161:555-568

van Oevelen C, Collombet S, Vicent G, Hoogenkamp M, Lepoivre C, Badeaux A, Bussmann L, Sardina JL, Thieffry D, Beato M, Shi Y, Bonifer C, Graf T (2015) C/EBPalpha activates pre-existing and de novo macrophage enhancers during induced pre-B cell transdifferentiation and myelopoiesis. Stem Cell Rep 5:232-247

Wang A, Yue F, Li Y, Xie R, Harper T, Patel NA, Muth K, Palmer J, Qiu Y, Wang J, Lam DK, Raum JC, Stoffers DA, Ren B, Sander M (2015) Epigenetic priming of enhancers predicts developmental competence of hESC-derived endodermal lineage intermediates. Cell Stem Cell 16:386-399

Wapinski OL, Vierbuchen T, Qu K, Lee QY, Chanda S, Fuentes DR, Giresi PG, Ng YH, Marro S, Neff NF, Drechsel D, Martynoga B, Castro DS, Webb AE, Sudhof TC, Brunet A, Guillemot F, Chang HY, Wernig M (2013) Hierarchical mechanisms for direct reprogramming of fibroblasts to neurons. Cell 155:621-635

Watts JA, Zhang C, Klein-Szanto AJ, Kormish JD, Fu J, Zhang MQ, Zaret KS (2011) Study of FoxA pioneer factor at silent genes reveals Rfx-repressed enhancer at $\mathrm{Cdx} 2$ and a potential indicator of esophageal adenocarcinoma development. PLoS genetics 7, e1002277 